\title{
Clinical and cost effectiveness of booklet based vestibular rehabilitation for chronic dizziness in primary care: single blind, parallel group, pragmatic, randomised controlled trial
}

\author{
(c) $\frac{(1)(8)}{\text { gy }}$ OPEN ACCESS
}

Lucy Yardley professor of health psychology ${ }^{1}$, Fiona Barker audiologist ${ }^{2}$, Ingrid Muller research assistant ${ }^{1}$, David Turner principal research fellow in health economics ${ }^{3}$, Sarah Kirby research fellow ${ }^{1}$, Mark Mullee medical statistician ${ }^{4}$, Anna Morris audiologist ${ }^{5}$, Paul Little professor of primary care research ${ }^{6}$

${ }^{1}$ Faculty of Human and Social Sciences, University of Southampton, Southampton SO17 1BJ, UK; ${ }^{2}$ Windsor ENT, Princess Margaret Hospital, Windsor, UK; ${ }^{3}$ Wessex Institute, Faculty of Medicine, University of Southampton ; ${ }^{4}$ Primary Care and Population Sciences, Faculty of Medicine, University of Southampton; ${ }^{5} \mathrm{NHS}$ Hampshire Primary Care Trust, Eastleigh, UK; ${ }^{6}$ Primary Care and Population Sciences, Faculty of Medicine, University of Southampton

\begin{abstract}
Objective To determine the clinical and cost effectiveness of booklet based vestibular rehabilitation with and without telephone support for chronic dizziness, compared with routine care.

Design Single blind, parallel group, pragmatic, randomised controlled trial.

Setting 35 general practices across southern England between October 2008 and January 2011.

Participants Patients aged 18 years or over with chronic dizziness (mean duration $>$ five years) not attributable to non-vestibular causes (confirmed by general practitioner) and that could be aggravated by head movement (confirmed by patient).

Interventions Participants randomly allocated to receive routine medical care, booklet based vestibular rehabilitation only, or booklet based vestibular rehabilitation with telephone support. For the booklet approach, participants received self management booklets providing comprehensive advice on undertaking vestibular rehabilitation exercises at home daily for up to 12 weeks and using cognitive behavioural techniques to promote positive beliefs and treatment adherence. Participants receiving telephone support were offered up to three brief sessions of structured support from a vestibular therapist.
\end{abstract}

Main outcome measures Vertigo symptom scale-short form and total healthcare costs related to dizziness per quality adjusted life year (QALY).
Results Of 337 randomised participants, 276 (82\%) completed all clinical measures at the primary endpoint, 12 weeks, and $263(78 \%)$ at one year follow-up. We analysed clinical effectiveness by intention to treat, using analysis of covariance to compare groups after intervention, controlling for baseline symptom scores. At 12 weeks, scores on the vertigo symptom scale in the telephone support group did not differ significantly from those in the routine care group (adjusted mean difference -1.79 ( $95 \%$ confidence interval -3.69 to 0.11 ), $P=0.064$ ). At one year, both intervention groups improved significantly relative to routine care (telephone support -2.52 ( -4.52 to -0.51 ), $P=0.014$; booklet only -2.43 ( -4.27 to -0.60$), P=0.010$ ). Analysis of cost effectiveness acceptability curves showed that both interventions were highly cost effective; at very Iow QALY values, the booklet only approach was most likely to be cost effective, but the approach with additional telephone support was most likely to be cost effective at QALY values more than $£ 1200$ ( $€ 1488$; \$1932). Using the booklet approach with telephone support, five (three to 12) patients would need to be treated for one patient to report subjective improvement at one year.

Conclusions Booklet based vestibular rehabilitation for chronic dizziness is a simple and cost effective means of improving patient reported outcomes in primary care.

Trial registration ClinicalTrials.gov NCT00732797. 


\section{Introduction}

Dizziness associated with vestibular dysfunction is a very common condition, especially among older patients. In large population studies, up to $25 \%$ of adults report current dizziness, ${ }^{1-3}$ and a screening test for poor balance due to vestibular dysfunction showed deficits in $35 \%$ of adults and $50 \%$ of those older than 60 years. ${ }^{4}$ Patients might be unconcerned about mild dizziness or balance deficits, but more than one in ten people of working age ${ }^{23}$ and one in five people older than 60 years $^{5}$ currently has dizziness that causes considerable interference with daily activities, medical consultation, or medication use. Peripheral vestibular disorder is the most common cause of dizziness presenting in primary care, but anxiety or other psychiatric disturbance is also frequently present, and a multifactorial syndrome is often identified in older people. ${ }^{126-13}$ Chronic dizziness associated with poor balance is a significant risk factor for falling and fear of falling, ${ }^{4}{ }^{14}$ which in turn results in substantial further limitation of activity, morbidity, and healthcare costs. ${ }^{15-17}$

There is now widespread consensus that an exercise based form of treatment known as "vestibular rehabilitation" or "balance retraining" is the most effective means of managing dizziness due to vestibular dysfunction. ${ }^{18-20}$ The central element of vestibular rehabilitation is a programme of graded exercises, consisting of eye, head, and body movements designed to stimulate the vestibular system. Initially, these movements provoke dizziness, but repetition for many weeks promotes neurological adaptation and compensation processes resulting in partial or complete resolution of symptoms and balance problems. ${ }^{21-23}$ The exercises can also help patients to overcome fear and avoidance of activities that elicit disorientation, and regain skill and confidence in balance. ${ }^{24-26}$

Vestibular rehabilitation has been recommended for a wide range of conditions, including peripheral vestibular disorder; benign paroxysmal positional vertigo; Ménière's disease (when spontaneous attacks are infrequent); multifactorial dizziness in older people; and dizziness associated with migraine, whiplash, or head injury. ${ }^{1825}{ }^{27-30}$ Currently, only a small fraction of eligible patients with dizziness ever receive vestibular rehabilitation, ${ }^{31} 32$ even though rehabilitation exercises are relatively simple and can be done at home. ${ }^{19} 2033$

In the only substantial trial of vestibular rehabilitation in primary care so far, $^{33}$ just 3\% (5/170) of participants had previously been offered rehabilitation, despite a mean duration of dizziness of eight years, yet two thirds of participants benefited from it in the trial. Typically, $80-90 \%$ of patients with dizziness are managed in primary care, ${ }^{6} 3134$ chiefly by reassurance and treatment for symptomatic relief. ${ }^{67313637}$ However, no drug in current use has well established curative or prophylactic value or is suitable for palliative use in the long term. ${ }^{7138}$ Access to vestibular rehabilitation usually involves a costly and lengthy referral process to secondary care for assessment by a variety of specialties, often including imaging, ${ }^{31} 323940$ and locating suitable trained therapists to teach exercises to patients can be difficult. ${ }^{20}$ Consequently, there is increasing pressure to explore alternative models of treatment delivery that can provide prompt and cost effective treatment to a larger proportion of patients. ${ }^{40}{ }^{41}$

Our previous trial of booklet based vestibular rehabilitation in primary care with support from trained practice nurses showed that this procedure could be a safe and effective mode of delivery, ${ }^{33}$ but primary care staff do not generally have the specialist skills and experience to diagnose and treat vestibular disorders and therefore could lack confidence to do so. ${ }^{39} 42$ This study therefore investigated other models of care that could be readily implemented and that do not need primary care staff to have additional training. One option is to consider using an existing pool of health professionals (including audiologists, physiotherapists, and hearing therapists) who have training and experience in vestibular rehabilitation, but these therapists are typically attached to specialist clinics rather than primary care. A potentially feasible and cost effective approach would be to give the rehabilitation booklets to patients in primary care and employ experienced therapists to provide structured remote support by telephone. If this model is implemented, it is first necessary to establish whether remote telephone support from an unfamiliar clinician can satisfactorily substitute the face-to-face support given by a familiar practice nurse that had proved effective in our previous trial. We also hypothesised that telephone support might prove unnecessary since the booklets were designed to give precise comprehensive support for patients to self manage their symptoms, ${ }^{43}$ and needed no specific additional therapist input. Consequently, we aimed to determine whether booklet based vestibular rehabilitation with expert telephone support was an effective and cost effective alternative to routine care, and explore the benefits of such rehabilitation without telephone support.

\section{Methods}

We did a single blind, three arm, parallel group, pragmatic, randomised controlled trial. Before commencing, the trial was approved by the National Research Ethics Service and was registered with ClinicalTrials.gov. The trial protocol has been published, ${ }^{44}$ and this paper follows CONSORT reporting guidelines for non-pharmacological, pragmatic trials. ${ }^{45}$ The trial steering committee agreed a detailed statistical and health economics analysis plan before data analysis.

\section{Participants and procedures}

We recruited patients between October 2008 and July 2009 from 35 general practices across southern England, including inner city, suburban, and rural practices. We used practice records to identify eligible patients 18 years or older with a complaint of dizziness during the past two years (box 1). Patients were reviewed by their general practitioner and excluded if the dizziness was attributed to non-vestibular causes or there were contraindications to treatment by vestibular rehabilitation. Patients identified as potentially suitable were sent invitation letters, and on return of their consent form to the research team, they were mailed the baseline questionnaire pack. On return of the baseline questionnaires, we excluded patients if their responses showed that they were no longer dizzy or their dizziness was not aggravated by rapid head movements (we used this item for screening because vestibular rehabilitation is designed primarily to treat dizziness provoked by movement).

An independent randomisation service allocated eligible patients (stratified for symptom severity) to one of the three intervention groups: self management booklet with telephone support from a vestibular therapist, self management booklet only, and routine medical care. Within each randomisation block of nine patients, those randomised to receive telephone support were then allocated to one of the three therapists. The trial administrator informed participants which intervention group they had been allocated to, sent vestibular rehabilitation booklets to participants in the active treatment groups, and informed therapists of patients that had been allocated to them. Participants, therapists, and the trial administrator could not be blinded to treatment allocation but the researchers who assessed and analysed outcomes remained blinded. Outcomes were assessed by use of 


\section{Box 1 Procedures for selection and assessment of participants}

1) Practice staff identified potentially suitable patients from their computerised databases using the search terms "vertigo", "dizziness", "Ménière's disease", "vestibular", "prochlorperazine", "cinnarizine", and "betahistine"

2) General practitioners reviewed patient selections. Exclusion criteria were non-labyrinthine cause of dizziness; medical contraindications for making necessary head movements (for example, severe cervical disorder); serious comorbidity (for example, life threatening condition, severe cognitive impairment); or the patient could not read, speak, or understand English

3) For patients identified as potentially suitable, practice staff sent an invitation letter, information sheet, consent form, refusal slip, and prepaid envelope to return the consent form or refusal slip to the administrator

4) The administrator posted the baseline questionnaire pack to consenting participants, to complete at home and return

5) On return of completed baseline questionnaire, the research team excluded patients before randomisation if they scored zero on the vertigo subscale of the vertigo symptom scale-short form, or if they answered "no" to the item asking whether their dizziness was aggravated by rapid head movements. Study identification numbers of eligible participants were emailed to an independent randomisation service

6) An independent randomisation service allocated participants to the three intervention arms using a block size of nine, stratifying by severity of symptoms on the vertigo symptom scale-short form (low severity $<12$ points, high severity $\geq 12$ points). Within each block of nine, patients randomised to receive telephone support were then randomised to one of three therapists. Allocations were emailed to trial administrator

7) The administrator sent participants a sheet informing them of their allocated intervention arm, together with a vestibular rehabilitation booklet if allocated to one of the active treatment arms, and sent therapists details of patients allocated to them

8) The administrator and research team sent patients self completion questionnaire packs by post at 12 weeks and 12 months. Non-respondents received one postal reminder, followed by a telephone reminder

9) Final telephone follow-up by blinded members of the research team; non-respondents asked to verbally complete single item, treatment benefit measure. Information on health service use collected from medical records after patients had completed study. Data entry (double entry of $10 \%$ of data)

self completion questionnaire packs at 12 weeks and one year (up to January 2011).

\section{Intervention groups}

All participants were informed that they were free to seek any care or treatment they wished throughout the trial. Participants allocated to the routine care group were informed that they could request the treatment booklet after completing the trial (that is, at one year follow-up). Participants in the active treatment groups received a validated booklet ${ }^{33} 43$ that explained how vestibular rehabilitation exercises could reduce or eliminate movement-provoked dizziness and provided instructions on how to perform them. The booklets are also available from the Ménière's Society UK. Participants allocated telephone support were offered a session of up to 30 minutes on commencing the exercise programme. Two follow-up sessions of up to 15 minutes were offered, one week and three weeks after starting the exercise programme. The booklet and support sessions drew on cognitive behavioural theory and techniques ${ }^{46-49}$ to maximise adherence to exercise (box 2).

\section{Measures}

All patient outcomes were measured at baseline (before randomisation), immediately after treatment (12 weeks), and at one year follow-up. We assumed the maximal impact would most probably be after 12 weeks, hence the primary outcome was total scores on the vertigo symptom scale-short form ${ }^{3}$ at 12 weeks' follow-up. Secondary outcome measures were subjective improvement in dizziness,$^{50}$ subscales of the vertigo symptom scale-short form, ${ }^{51}$ dizziness handicap inventory,${ }^{52}$ subscales of the hospital anxiety and depression scale, ${ }^{53}$ and EuroQol EQ-5D ${ }^{54}$ (box 3). At baseline, we asked participants to report their demographic characteristics (age, sex, age when leaving school, education after school), duration of dizziness, and health service use during the past year. We assessed adherence to treatment at 12 weeks in the active treatment groups using the validated problematic experiences of therapy scale,$^{43}$ and at one year follow-up, we asked participants whether they had continued to use the vestibular rehabilitation exercises. We recorded adverse events reported by participants using the Southampton University Hospitals Trust form.
Economic costs of the interventions comprised the purchase price of the booklets (since we assumed organisations implementing this intervention would use the existing booklet rather than develop a new booklet) and costs per minute for each therapist (including employer and overhead costs), increased by a multiplier calculated from the ratio of client contact time to total time obtained from a published source of unit costs. ${ }^{55}$ Resource use of dizziness related healthcare was obtained at one year follow-up by a blinded researcher, from the medical records. Any doubt as to whether the contact was dizziness related was clarified by expert advice from the steering committee members. Each therapist recorded time spent on telephone consultations. These data were combined with unit costs obtained from routinely used published sources (web appendix). ${ }^{55}$ All costs were in 2009-10 United Kingdom pounds sterling.

\section{Sample size}

The study was powered for a comparison between the participants allocated to receive booklet self management with telephone support and those allocated to receive routine care. Assuming that booklet self management with telephone support produced a treatment effect as large as that found in our previous primary care trial (effect size $\mathrm{d}=0.41$ ) ${ }^{33}$ we calculated that we would need 110 patients per group to test a two tailed hypothesis with $80 \%$ power and 5\% significance level, allowing for 15 patients to drop out of each condition. Although we also intended to compare booklet self management only with routine care, we did not specifically power the trial for this comparison because we assumed that booklet self management only might have a smaller effect size and thus a larger trial would be needed to reliably detect this.

\section{Statistical analysis}

We did all clinical effectiveness analyses on an intention to treat basis, using Stata version 11.1. The primary analysis compared symptom scores from the vertigo symptom scale-short form at 12 weeks between patients randomised to booklet self management with telephone support and those randomised to routine care using analysis of covariance, adjusting for the symptom score at baseline (the stratification variable). We also evaluated all other continuous outcomes using analysis of 


\section{Box 2: Content and implementation of active treatment arms}

\section{Booklet description}

1) First section of booklet designed to optimise adherence by promoting accurate perceptions of symptoms and treatment, ensuring positive but realistic expectations of progress and outcome, citing positive outcomes in people with similar problems, and addressing common concerns

2) Instructions given on how to use a weekly self test to tailor a set of vestibular rehabilitation exercises to the patient's particular symptoms. Instructions to carry out exercises for 5-10 minutes twice daily for 12 weeks, or until symptoms resolve

3) Instructions given on how to monitor progress (using the weekly self test) and modify the exercise programme as appropriate. Tools provided to support planning and self monitoring of exercise performance. Advice on gradual resumption of activities previously avoided

Support session description

1) Initial session focused on ensuring informed and appropriate implementation of the programme, eliciting and addressing concerns, agreeing goals, and encouraging adherence. Follow-up sessions focused on adherence, and overcoming any barriers to non-adherence 2) Therapists were audiologists with training in vestibular rehabilitation and varying levels of experience. Two hour training session given to instruct on using manual to standardise support. Self completion checklist used to ensure manual was followed and to check treatment delivery

3) All telephone consultations recorded. Random selection of $10 \%$ of sessions analysed to validate treatment delivery assessment by therapist checklists

\section{Box 3: Details of measures}

\section{Vertigo symptom scale-short form}

Primary outcome; based on frequency of 15 dizziness related symptoms during the past month on a scale from 0 (no symptoms) to 4 (symptoms most days). Improvement can therefore reflect either fewer or less frequent symptoms. Scored 0 (best score) to 60.

\section{Vertigo-balance subscale}

Separate measure comprising items $1,3,4,6,8,10,13$, and 15 from vertigo symptom scale-short form. Scored 0 (best score) to 32 .

Autonomic-anxiety subscale

Separate measure comprising items 2, 5, 7, 9, 11, 12, and 14 from vertigo symptom scale-short form. Scored 0 (best score) to 28.

\section{Subjective improvement in health}

Validated single item ("your dizziness or unsteadiness now") asking participants to state on 6 point scale (dichotomised for analysis) whether, during the past week, they had felt better, much the same, or worse than when completing the baseline assessment. Scale dichotomised as improvement (best score) versus no improvement (same or worse) for preplanned analyses.

\section{Dizziness handicap inventory}

Measures the functional, physical, and emotional impact of dizziness by summing whether participants experienced 25 "problems" on 3 point scale ( $\mathrm{no}=0$, sometimes $=2$, yes $=4$ ). Scored 0 (best score) to 100 .

Hospital anxiety and depression scale

Anxiety subscale

Measures the level of anxiety experienced in relation to physical illness by summing seven anxiety items on a scale from 0 (no symptoms) to 3. A score of 8 or more is considered above the threshold for possible clinical anxiety levels. Scored 0 (best score) to 21.

\section{Depression subscale}

Measures the level of depression experienced in relation to physical illness by summing seven depression items on a scale from 0 (no symptoms) to 3 . A score of 8 or more is considered above the threshold for possible clinical depression levels. Scored 0 (best score) to 21 .

\section{EuroQol EQ-5D}

European quality of life instrument used to generate quality adjusted life years (QALY) for cost effectiveness analysis. Sums five items on quality of life (scoring from 1 (no problem) to 3 ) and then converts to weighted index. Scored 0 (worst score) to 1.

\section{Problematic experiences of therapy scale}

Includes 12 items asking about the extent to which adherence was prevented by socially acceptable reasons (not analysed here; used to encourage disclosure of non-adherence), then assesses how often participant exercised weekly and daily and how many weeks exercises carried out for. Response options varied for each aspect of adherence.

covariance, adjusting for the level of the relevant outcome variable at baseline as well as baseline symptom score (the stratification variable). Binary group outcomes were compared using logistic regression, also adjusting for baseline symptom score. All these analyses were repeated for outcomes at one year. We did sensitivity analyses on the vertigo symptom scale-short form to adjust for differences in baseline measures and increase the number of participants available for analysis by replacing missing data using multiple imputation. The web appendix shows details of the sensitivity and per protocol analyses.

\section{Cost effectiveness analyses}

The principal economic evaluation was a cost utility study using cost per QALY, derived from EQ-5D scores at 0, 12 weeks, and one year after randomisation. We also estimated the cost per point change in the primary outcome (that is, the vertigo symptom scale-short form). Since our analysis was limited to the one year of follow-up, neither costs nor benefits were discounted. The perspective of the analysis was that of the UK's health service. Our base case results only included patients for whom we had complete data for QALY scores, dizziness related costs, and therapist costs. We used bootstrapping, with 5000 samples, to estimate costs, QALYs (adjusted for baseline EQ-5D 
scores), and change in the vertigo symptom scale-short form. If one intervention was more effective and more costly than another, we calculated an incremental cost effectiveness ratio. ${ }^{57}$ We also used the 5000 bootstrapped samples to estimate cost effectiveness acceptability curves. These curves show the probability of each study group being the most cost effective option at different values of a QALY. We included EQ-5D for the purpose of comparative cost effectiveness analyses based on QALYs; the study was not powered to detect between group differences in EQ-5D, which was expected to be relatively insensitive to improvement in dizziness (web appendix). We did analyses using PASW version 18, and Excel for bootstrapping analyses.

\section{Results}

\section{Sample characteristics and intervention delivery}

We randomised 337 participants; at 12 weeks, 276 (82\%) completed the follow-up questionnaires, including the primary outcome, whereas $312(93 \%)$ responded to the single item assessment of subjective improvement. At 12 months, 263 participants (78\%) completed the follow-up questionnaires and $295(88 \%)$ completed the single item assessment of subjective improvement. Figure $1 \Downarrow$ shows the flow of participants through the trial. Of 5223 patients sent an invitation, most did not reply (3250, 62\%); but among the 1461 (28\%) who completed the refusal slip, a large proportion $(1052,72 \%)$ reported that they were no longer dizzy. Table $1 \Downarrow$ shows participants' characteristics at baseline. We observed baseline differences between study groups for sex, age when leaving school, duration of dizziness, consultation with a healthcare professional in the past year, and number of patients exceeding the threshold for anxiety or depression on the hospital anxiety and depression scale. As a result, we adjusted our sensitivity analysis for these imbalances (web appendix).

The first telephone support session was delivered to 82 (73\%) participants in the telephone support group, and 66 (59\%) received all three support sessions. There was good agreement between therapist checklist ratings of delivery of target intervention components and independent ratings based on recorded sessions $(\kappa=0.82)$. Checklists indicated that most of the core intervention components (mean 12.0 components of 15 , standard deviation 1.62) and optional components (14.2 components of 24, 3.12) were delivered.

Adherence to the full programme of exercises was reported by $49(44 \%)$ participants randomised to booklet self management with telephone support and 38 (34\%) randomised to booklet self management only. This difference in proportions was not significant (95\% confidence interval $-3 \%$ to $22 \%, \mathrm{P}=0.119)$, but exploratory retrospective analyses showed that patients in the telephone support group reported carrying out the exercises at a greater intensity than those in the group receiving booklet self management only (web appendix). Half the patients in the booklet treatment groups $(n=113)$ reported using the exercises at some point after the end of the initial 12 week treatment period, with a third $(n=75)$ reporting repeated use.

\section{Effectiveness analyses}

At 12 weeks, all groups showed some improvement in the vertigo symptom scale-short form (table $2 \Downarrow$ ). The increased improvement seen in participants allocated to receive booklet self management with telephone support, compared with the routine care group, failed to reach statistical significance. However, this comparison was significant $(\mathrm{P}=0.041)$ in a sensitivity analysis that adjusted for differences in baseline measures and replaced missing data using multiple imputation (web appendix). By one year, both treatment groups showed greater improvement in scores on the vertigo symptom scale-short form than the routine care group (table $3 \Downarrow$ ).

Subjective improvement was also reported by a larger proportion of the treatment groups than the routine care group, at both 12 week and one year follow-up (tables 2 and 3). For the primary comparison between booklet self management with telephone support and routine care, the point estimate for the absolute difference of $22.0 \%$ (95\% confidence interval $7.3 \%$ to $36.8 \%$ ) indicated that five (three to 12) patients would need to be treated for one patient to report subjective improvement at one year. More detailed examination of the pattern of subjective improvement indicated that $57(60 \%)$ of 95 patients randomised to booklet self management with telephone support reported feeling much better or completely well at one year, compared with 33 (33\%) of 99 in the usual care group (fig $2 \Downarrow$ ). Fewer patients in this group (five (5\%) of 95) than in the usual care group (15 $(15 \%)$ of 99$)$ reported worse symptoms at one year follow-up; outcomes for the group allocated to receive booklet self management only were intermediate.

At 12 weeks, compared with routine care, the group allocated to receive booklet self management with telephone support improved on the autonomic anxiety subscale of the vertigo symptom scale. At one year, both treatment groups showed improvement on the autonomic anxiety subscale compared with the routine care group. We saw no group differences on the vertigo balance subscale at either time point. Scores for the dizziness handicap inventory improved significantly in both treatment groups relative to routine care at one year follow-up, although not at 12 weeks. At one year (but not 12 weeks), scores on the hospital anxiety and depression scale improved in the patients randomised to booklet self management with telephone support, but only relative to routine care. As expected, we saw no significant group differences in EQ-5D scores. Retrospective exploratory analyses comparing the two treatment groups showed similar outcomes for almost all measures (table 10 in web appendix).

\section{Reported adverse events and adverse reactions}

We discussed any adverse events and reactions with the trial steering committee, and dizziness related medical resource use was similar in the treatment and control groups. In the routine care group, no adverse events were reported (adverse reactions were not applicable). Patients who received booklet self management only did not report any adverse events or serious adverse reactions. However, they did report some adverse reactions caused by the exercises: worsened migraines $(n=1)$, leg pain while standing $(n=1)$, and neck discomfort $(n=2)$. The group that received booklet self management with telephone support also reported no adverse events or serious adverse reactions, although one participant fell after feeling dizzy from performing the exercises, breaking a foot bone.

\section{Cost effectiveness analyses}

We had complete data for 236 patients for QALY, dizziness related healthcare use, and booklet and therapist related costs. One case was excluded as an outlier because of an inpatient stay related to dizziness; since this case occurred in the control group, we considered this exclusion a conservative assumption, because including this case would have increased the average cost and hence would have favoured the treatment groups. Total costs 
were similar for the routine care and active treatment groups (table $4 \Downarrow$ ). The intervention for booklet self management with telephone support incurred the highest cost.

Owing to the group differences in EQ-5D scores at baseline, we presented results after controlling for this baseline characteristic. Both QALYs and point change on the vertigo symptom scale-short form showed increased effectiveness relative to routine care with both active interventions. Booklet self management with telephone support was the most cost effective. Compared with booklet self management only, the group with additional telephone support generated QALYs and point changes on the vertigo symptom scale-short form at $£ 1363$ (€1690; \$2194) and £129, respectively. Figure $3 \Downarrow$ shows the cost effectiveness acceptability curve for the cost-QALY analysis; the routine care group rapidly became the least likely approach to be cost effective. At lower QALY values, booklet self management only was most likely to be cost effective, but the booklet approach with additional telephone support was the most likely to be cost effective at QALY values greater than about $£ 1200$.

\section{Discussion}

We hypothesised that in patients with chronic dizziness, those receiving booklet self management for vestibular rehabilitation exercises with telephone support would report fewer symptoms than those receiving routine care at 12 weeks. This primary comparison failed to reach significance, but by one year follow-up, patients allocated booklet self management (with or without telephone support) clearly improved relative to those allocated routine care, by reporting greater subjective improvement, fewer symptoms related to dizziness, and a reduced handicap related to dizziness. Cost effectiveness analyses confirmed that at one year follow-up, both booklet interventions were highly cost effective.

Currently, there is poor access to vestibular rehabilitation in primary care, which can result in prolonged symptomatology, elevated levels of handicap, and ultimately expensive and unnecessary referrals to secondary care. ${ }^{31} 324058$ Although many patients presenting in primary care with dizziness have a good prognosis, these trial results suggest that booklet based vestibular rehabilitation could have a valuable role in a stepped care approach for a substantial proportion of patients with more persistent and distressing dizziness symptoms. This intervention could reduce the number of patients who need referral to secondary care for more intensive investigation and management - particularly since only a small minority of patients with dizziness are willing to attend secondary care for testing and rehabilitation. ${ }^{50}$

\section{Strengths and weaknesses of the study}

This study was unique in two major respects. Firstly, it evaluated a new model of treatment provision for chronic dizziness, by means of booklet based management in primary care with or without remote expert telephone support, and we have shown this intervention to be an acceptable and effective method of managing dizziness. This study illustrates the potential of a model of support for patient self management of long term conditions that has not yet been widely investigated, ${ }^{59}$ but could well prove suitable for other chronic or relapsing conditions.

Secondly, we examined the cost effectiveness of vestibular rehabilitation. We have established that it is a cost effective treatment when provided using our inexpensive method of booklet based self management in primary care. Even with additional telephone support, the cost per QALY of this approach was less than a tenth of the NHS threshold for willingness to pay. ${ }^{60}$ No previous trial of vestibular rehabilitation in secondary care has evaluated the cost effectiveness of this method of delivery. However, in our study, provision of booklet self management with telephone support cost only $£ 25$ more than routine care, which compares favourably with an average total healthcare cost of $£ 196$ for a patient with benign paroxysmal positional vertigo referred to secondary care. ${ }^{39}$ Furthermore, this study was much more substantial and methodologically rigorous than most trials of vestibular rehabilitation in secondary care have been. ${ }^{23}$ We achieved good follow-up rates over an extended period of time, and confirmed all healthcare costs objectively by inspecting medical records for every patient. Although we did not use objective measures of balance, we considered these measures unnecessary because our previous trials ${ }^{3361}$ confirmed that subjective improvement from booklet based vestibular rehabilitation was accompanied by an improvement in objective outcomes (that is, improved postural control). Therefore, the focus of this study was on the cost effectiveness of achieving patient reported benefit.

A potential limitation of the study was its low uptake rate $(<10 \%$ of patients invited to participate). However, nearly three quarters of patients who gave a reason for non-participation stated that they were no longer dizzy. This reason could also have been true of most non-respondents, since an 18 month follow-up of patients with dizziness in the community found that less than half had continued to experience significant dizziness. ${ }^{62}$ The proportion of participants in this community survey who were willing to attend secondary care for testing and rehabilitation was also less than $10 \% .^{50}$ Clearly, it is those patients with more persistent and distressing symptoms in primary care who could value and benefit from the provision of vestibular rehabilitation. The cost of providing the booklet is negligible and hence could prove cost effective even if only a minority of patients benefit, but telephone support might be neither necessary nor cost effective to offer to patients when they first consult for acute dizziness.

It was not possible to blind participants to the intervention group that they were in, and patients in the routine care group might have been less likely to report subjective improvement if they felt that they had not received active treatment. Non-specific psychological effects of treatment, such as reassurance and positive outcome expectations, probably contribute to outcome in patients with dizziness, ${ }^{43}$ and were explicitly maximised by our booklet. However, many trials have shown that improvement in subjective outcomes after vestibular rehabilitation is accompanied by improvements in objective measures of balance function, ${ }^{21} 2333$ and therefore cannot be attributed entirely to psychological effects.

A strength of the study was that inclusion criteria were broad, and the findings might be generalisable to a wide range of patients with dizziness in primary care. A potential limitation was that precise diagnoses were not obtained, and therefore outcomes cannot be related to patient diagnosis. However, achieving a definitive diagnosis in primary care is not often possible, ${ }^{32}$ and a precise diagnosis might be unnecessary in view of the effectiveness of vestibular rehabilitation for various causes. ${ }^{20} 30$

\section{Explanations and implications}

Although we expected, on the basis of previous trials, that improvement due to the intervention would be sustained, we did not anticipate that the longer term benefit would be greater than the short term benefit. Nevertheless, there are plausible 
explanations for the sustained and even improved benefit occurred at one year follow-up. Some other studies have reported better outcomes at longer follow-up time points ${ }^{63}$ and have recommended that vestibular rehabilitation be carried out in the longer term. Self management techniques could provide a useful long term coping strategy for patients with chronic symptoms (including those with recurrent benign paroxysmal positional vertigo, or with fluctuating symptoms due to migraine or Ménière's disease ${ }^{30} 39436365-67$ ) and could reduce anxiety about symptom recurrence. In our study, the mean duration of symptoms at baseline was over five years, and half the sample continued to use the exercises after the initial 12 week treatment period, consistent with a pattern of sustained management of chronic dizziness.

The interventions clearly had psychological benefits, particularly the telephone support intervention, which resulted in considerable decreases in both anxiety and depression at one year follow-up. Strong evidence indicates that anxiety about symptoms has an important role in perpetuating handicap and distress in patients with dizziness, even if a vestibular rather than psychiatric origin for the dizziness is confirmed ${ }^{68-70}$ Shared, central neurological pathways might explain the commonly observed association between dizziness, anxiety, and migraine $;^{71}{ }^{72}$ therefore, interventions should address the perpetuation and augmentation of symptoms by anxiety. ${ }^{18} 73$ Our vestibular rehabilitation package was designed to reduce anxiety by reassuring patients that their symptoms were benign, tolerable, and controllable, as well as create safe opportunities to habituate to them gradually. ${ }^{26}$

Some inconclusive results indicated that expert telephone support might be more effective than self management for some patients. The group with additional telephone support had higher adherence to the exercises, significant improvement in anxiety and depression, and a higher probability of being the most cost effective treatment (except at low QALY values). Nevertheless, the differences between treatment groups were marginal and mainly not significant. Further research should establish the optimal level and mode of therapist support ${ }^{74}$ which might vary for different subgroups of patients (more than a quarter of our participants did not take up the telephone support offered), and compare the effectiveness of support provided by different groups of health professionals (for example, audiologists, physiotherapists, or trained practice nurses).

\section{Conclusions and practice implications}

This trial has shown two simple and cost effective means of managing chronic dizziness in primary care for a group of patients who are currently very poorly served. At a minimum, the simple provision of a booklet explaining to patients how to self manage their symptoms using vestibular rehabilitation exercises seems to have lasting benefits, without incurring any additional resource use relative to routine care. This approach seems to benefit a substantial proportion of patients with chronic dizziness that is aggravated by head movement, in whom a non-vestibular cause has been excluded. To enhance the effects of this intervention, telephone support from a suitably trained therapist might be useful for patients who need and want the additional support. Although telephone support is a little more costly, the enhanced approach is highly cost effective, and would not be difficult to implement within the health service.

We thank Adolfo Bronstein for providing expert medical advice; James Raftery and Debbie King for their contributions to the study design and funding proposal; Natasha Harrington-Benton and Humphrey Bowen from the Ménière's Society, UK, for providing the patient perspective from inception to completion; Gemma Court for providing telephone support; and Victoria Hayter, who was the trial administrator.

Contributors: LY and FB conceived the study. LY, FB, SK, and PL designed the study and secured funding. LY, FB, and AEM designed the interventions. IM and SK managed all study procedures (ethics and governance, recruitment, patient assessment, data management). FB, AEM, and PL were responsible for ensuring clinical safety and appropriateness of implementation. MM planned and undertook the clinical effectiveness statistical analysis. DT planned and undertook the cost effectiveness analysis. LY drafted the manuscript with input from all authors. All the authors had access to the data and analysis and approved the final manuscript. LY is the guarantor.

Funding: The trial was funded by the National Institute for Health Research under its Research for Patient Benefit Programme (grant PB-PG-0107-12069). The study was sponsored by the University of Southampton. The sponsor and the funder of the study had no role in the study design, data collection and analysis, interpretation or reporting of this work, or the decision to submit the work for publication. All authors are independent of the funding source.

Competing interests: All authors have completed the Unified Competing Interest form at www.icmje.org/coi_disclosure.pdf (available on request from the corresponding author) and declare: financial support from the National Institute for Health Research and the University of

Southampton; no financial relationships with any organisations that might have an interest in the submitted work in the previous three years; no other relationships or activities that could appear to have influenced the submitted work.

Ethical approval: Ethical approval for this trial was granted by the National Research Ethics Service, reference 08/H0504/31.

Data sharing: The dataset and coding manual will be available from the corresponding author once all planned analyses have been completed and published. Consent was not obtained but the dataset is anonymised and risk of identification is very low.

Kroenke K, Hoffman RM, Einstadter D. How common are various causes of dizziness? A critical review. South Med J 2000;93:160-7.

2 Neuhauser HK, Radtke A, Von Brevern M, Lezius F, Feldmann M, Lempert T. Burden of dizziness and vertigo in the community. Arch Int Med 2008;168:2118-24.

3 Yardley L, Owen N, Nazareth I, Luxon L. Prevalence and presentation of dizziness in a general practice community sample of working age people. Br J Gen Pract 1998;48:1131-5.

4 Agrawal Y, Carey JP, Santina CCD, Schubert MC, Minor LB. Disorders of balance and vestibular function in US adults: data from the National Health and Nutrition Examination Survey, 2001-2004. Arch Int Med 2009;169:938-44.

5 Sloane $\mathrm{P}$, Blazer D, George LK. Dizziness in a community elderly population. J Am Geriatr Soc 1989;37:101-8

6 Bird JC, Beynon GJ, Prevost AT, Baguley DM. An analysis of referral patterns for dizziness in the primary care setting. Br J Gen Pract 1998;48:1828-32.

7 Colledge NR, Barr-Hamilton RM, Lewis SJ, Sellar RJ, Wilson JA. Evaluation of investigations to diagnose the cause of dizziness in elderly people: a community based controlled study. BMJ 1996;313:788-92.

8 Hanley K. Symptoms of vertigo in general practice: a prospective study of diagnosis. $B$ $J$ Gen Pract 2002;52:809.

9 Kao AC, Nanda A, Williams CS, Tinetti ME. Validation of dizziness as a possible geriatric syndrome. J Am Geriatr Soc 2001;49:72-5.

10 Sloane PD, Coeytaux RR, Beck RS, Dallera J. Dizziness: state of the science. Ann Int Med 2001;134:823-32.

11 Tinetti ME, Williams CS, Gill TM. Dizziness among older adults: a possible geriatric syndrome. Ann Int Med 2000;132:337-44.

12 Yardley L, Burgneay J, Nazareth I, Luxon L. Neuro-otological and psychiatric abnormalities in a community sample of people with dizziness: a blind, controlled investigation. J Neurol Neurosurg Psychiatr 1998;65:679-84.

13 Hanley K, O'Dowd T. Symptoms of vertigo in general practice: a prospective study of diagnosis. Br J Gen Pract 2002;52:809-12.

14 Pothula VB, Chew F, Lesser THJ, Sharma AK. Falls and vestibular impairment. Clin Otolaryngol 2004;29:179-82.

15 Murphy SL, Dubin JA, Gill TM. The development of fear of falling among community-living older women: predisposing factors and subsequent fall events. J Gerontol A: Biol Sci Med Sci 2003;58:M943.

16 Scuffham P, Chaplin S, Legood R. Incidence and costs of unintentional falls in older people in the United Kingdom. J Epidemiol Community Health 2003:57:740.

17 Stevens JA, Corso PS, Finkelstein EA, Miller TR. The costs of fatal and non-fatal falls among older adults. Inj Prev 2006;12:290-5.

18 Black FO, Pesznecker SC. Vestibular adaptation and rehabilitation. Curr Opin Otolaryngol Head Neck Surg 2003;11:355.

19 Cohen HS, Kimball KT. Increased independence and decreased vertigo after vestibular rehabilitation. Otolaryngol Head Neck Surg 2003;128:60-70.

20 Wrisley DM, Pavlou M. Physical therapy for balance disorders. Neurol Clin 2005;23:855-74. 


\section{What is already known on this topic}

Dizziness associated with vestibular dysfunction is common and can cause considerable anxiety, limitation of activity, and risk of falling Vestibular rehabilitation (comprising simple exercises) is the most effective treatment for dizziness due to vestibular dysfunction Currently, very few eligible patients with dizziness are taught vestibular rehabilitation exercises, even though these exercises can be done at home

\section{What this study adds}

Booklets teaching vestibular rehabilitation exercises were highly cost effective compared with routine care in treating patients with chronic dizziness in primary care

21 Strupp M, Arbusow V, Maag KP, Gall C, Brandt T. Vestibular exercises improve central vestibulospinal compensation after vestibular neuritis. Neurology 1998;51:838-44.

22 Hall CD, Cox LC. The role of vestibular rehabilitation in the balance disorder patient. Otolaryngol Clin North Am 2009;42:161-9.

23 Hillier SL, Hollohan V. Vestibular rehabilitation for unilateral peripheral vestibular dysfunction. Cochrane database of systematic reviews (Online) 2007;4:CD005397.

24 Beidel DC, Horak FB. Behavior therapy for vestibular rehabilitation. J Anxiety Disord 2001;15:121-30

25 Furman JM, Raz Y, Whitney SL. Geriatric vestibulopathy assessment and management. Curr Opin Otolaryngol Head Neck Surg 2010;18:386.

26 Yardley L. Overview of psychologic effects of chronic dizziness and balance disorders. Otolaryngol Clin North Am 2000:33:603-16.

27 Gottshall KR, Topp SG, Hoffer ME. Early vestibular physical therapy rehabilitation for Ménière's disease. Otolaryngol Clin North Am 2010;43:1113-9.

28 Gurr B, Moffat N. Psychological consequences of vertigo and the effectiveness of vestibular rehabilitation for brain injury patients. Brain Inj 2001;15:387-400.

29 Hansson EE, Monsson NO, Ringsberg KAM, Hakansson A. Dizziness among patients with whiplash-associated disorder: a randomized controlled trial. J Rehabil Med 2006:38:387-90.

30 Hansson EE. Vestibular rehabilitation-for whom and how? A systematic review. Adv Physiother 2007;9:106-16.

31 Jayarajan V, Rajenderkumar R. A survey of dizziness management in general practice. $J$ Laryngol Otol 2003;117:599-604

32 Polensek SH, Sterk CE, Tusa RJ. Screening for vestibular disorders: a study of clinicians' compliance with recommended practices. Med Sci Monit 2008;14:CR238.

33 Yardley L, Donovan-Hall M, Smith HE, Walsh BM, Mullee M, Bronstein AM. Effectiveness of primary care-based vestibular rehabilitation for chronic dizziness. Ann Int Med 2004;141:598-605

34 Hannaford PC, Simpson JA, Bisset AF, Davis A, McKerrow W, Mills R. The prevalence of ear, nose and throat problems in the community: results from a national cross-sectional postal survey in Scotland. Fam Pract 2005;22:227-33.

35 Nazareth I, Landau S, Yardley L, Luxon L. Patterns of presentations of dizziness in primary care-a cross-sectional cluster analysis study. J Psychosom Res 2006;60:395-401.

36 Brandt T. Management of vestibular disorders. J Neurol 2000;247:491-9.

37 Ahmed S, Mayo NE, Wood-Dauphinee S, Hanley JA, Cohen SR. Response shift influenced estimates of change in health-related quality of life poststroke. J Clin Epidemiol 2004;57:561-70.

38 Rascol O, Hain TC, Brefel C, Benazet M, Clanet M, Montastruc JL. Antivertigo medications and drug-induced vertigo. A pharmacological review. Drugs 1995;50:777-91.

39 Fife D, Fitzgerald JE. Do patients with benign paroxysmal positional vertigo receive promp treatment? analysis of waiting times and human and financial costs associated with current practice. Int J Audiol 2005;44:50-7.

40 Department of Health. Provision of adult balance services: a good practice guide. Department of Health, 2009.

41 Lee A, Jones G, Corcoran J, Premachandra P, Morrison GA. A UK hospital based multidisciplinary balance clinic run by allied health professionals: first year results. $J$ Laryngol Otol 2006;1:1-7.

42 Polensek SH, Tusa RJ, Sterk CE. The challenges of managing vestibular disorders: a qualitative study of clinicians experiences associated with low referral rates for vestibular rehabilitation. Int J Clin Pract 2009;63:1604-12.

43 Yardley L, Kirby S. Evaluation of booklet-based self-management of symptoms in Ménière's disease: a randomized controlled trial. Psychosom Med 2006;68:762-9.

44 Yardley L, Kirby SE, Barker F, Little P, Raftery J, King D , et al. Study protocol: an evaluation of the cost-effectiveness of booklet-based self-management of dizziness in primary care, with and without expert telephone support. BMC Ear Nose Throat Disord 2009;9:13.

45 Zwarenstein M, Treweek S, Gagnier JJ, Altman DG, Tunis S, Haynes B, et al. Improving the reporting of pragmatic trials: an extension of the CONSORT statement. BMJ 2008;337:a2390.

46 Myers LB, Midence K. Adherence to treatment in medical conditions. Harwood Academic Publishers, 1998.

47 Resnick B. A seven step approach to starting an exercise program for older adults. Patient Ed Counsel 2000;39:243-52.

48 Bandura A. Self-efficacy: the exercise of control. W H Freeman, 1997.

49 Andersson G, Yardley L. Combined cognitive-behavioural and physiotherapy treatment of dizziness: a case report. Behav Cogn Psychother 1998;26:365-9.
50 Yardley L, Burgneay J, Andersson G, Owen N, Nazareth I, Luxon L. Feasibility and effectiveness of providing vestibular rehabilitation for dizzy patients in the community. Clin Otolaryngol 1998;23:442-8.

51 Wilhelmsen K, Strand LI, Nordahl SHG, Eide GE, Ljunggren AE. Psychometric properties of the vertigo symptom scale short form. BMC Ear Nose Throat Disord 2008:8:2.

52 Jacobson GP, Newman CW. The development of the dizziness handicap inventory. Arch Otolaryngol Head Neck Surg 1990;116:424-7.

53 Zigmond AS, Snaith RP. The hospital anxiety and depression scale. Acta Psychiatr Scand 1983;67:361-70.

54 The EuroQol Group. EuroQol—a new facility for the measurement of health-related quality of life. Health Policy 1990;16:199-208.

55 Curtis L, Netten V. Unit costs of health and social care 2010. Personal Social Services Research Unit, University of Kent, 2010.

56 Department of Health. NHS reference costs 2009-2010. Department of Health, 2011.

57 Gold MR, Siegel JE, Russell LB, Weinstein MC. Cost-effectiveness in health and medicine. Oxford University Press, 1996

58 Bamiou DE, Davies RA, McKee M, Luxon LM. Symptoms, disability and handicap in unilateral peripheral vestibular disorders: Effects of early presentation and initiation of balance exercises. Scand Audiol 2000;29:238-44.

59 Muller I, Yardley L. Telephone-delivered cognitive behavioural therapy: a systematic review and meta analysis. J Telemed Telecare 2011;17:177-84.

60 Andersson G, Yardley L, Luxon L. A dual-task study of interference between mental activity and control of balance. Am J Otol 1998;19:632-7.

61 Yardley L, Beech S, Zander L, Evans T. A randomized controlled trial of exercise therapy for dizziness and vertigo in primary care. Br J Gen Pract 1998;48:1136-40.

62 Nazareth I, Yardley L, Owen N, Luxon L. Outcome of symptoms of dizziness in a general practice community sample. Fam Pract 1999;16:616-8.

63 Enticott JC, Vitkovic JJ, Reid B, O'Neill P, Paine M. Vestibular rehabilitation in individuals with inner-ear dysfunction: a pilot study. Audiol Neurotol 2007;13:19-28.

64 Krebs DE, Gill-Body KM, Parker SW, Ramirez JV, Wernick MR. Vestibular rehabilitation useful but not universally so. Otolaryngol Head Neck Surg 2003;128:240-50.

65 Helminski JO, Janssen I, Hain TC. Daily exercise does not prevent recurrence of benign paroxysmal positional vertigo. Otol Neurotol 2008;29:976.

66 Steenerson RL, Cronin GW. Comparison of the canalith repositioning procedure and vestibular habituation training in forty patients with benign paroxysmal positional vertigo. Otolaryngol Head Neck Surg 1996;114:61-4.

67 Furman JM, Balaban CD, Jacob RG, Marcus DA. Migraine-anxiety related dizziness (MARD): a new disorder? J Neurol Neurosurg Psychiatr 2005;76:1

68 Godemann F, Koffroth C, Neu P, Heuser I. Why does vertigo become chronic after neuropathia vestibularis? Psychosom Med 2004;66:783-7.

69 Monzani D, Casolari L, Guidetti G, Rigatelli M. Psychological distress and disability in patients with vertigo. J Psychosom Res 2001;50:319-23.

70 Pollak L, Klein C, Rafael S, Vera K, Rabey JM. Anxiety in the first attack of vertigo. Otolaryngol Head Neck Surg 2003;128:829-34.

71 Balaban CD, Thayer JF. Neurological bases for balance-anxiety links. J Anxiety Disord 2001;15:53-79.

72 Furman JM, Jacob RG. A clinical taxonomy of dizziness and anxiety in the otoneurological setting. J Anxiety Disord 2001;15:9-26.

73 Andersson G, Asmundson GJG, Denev J, Nilsson J, Larsen HC. A controlled trial of cognitive-behavior therapy combined with vestibular rehabilitation in the treatment of dizziness. Behav Res Ther 2006;44:1265-73.

74 Kao CL, Chen LK, Chern CM, Hsu LC, Chen CC, Hwang SJ. Rehabilitation outcome in home-based versus supervised exercise programs for chronically dizzy patients. Arch Gerontol Geriatr 2010:51:264-7.

\section{Accepted: 14 March 2012}

\section{Cite this as: BMJ 2012;344:e2237}

This is an open-access article distributed under the terms of the Creative Commons Attribution Non-commercial License, which permits use, distribution, and reproduction in any medium, provided the original work is properly cited, the use is non commercial and is otherwise in compliance with the license. See: http://creativecommons.org/licenses/by$\mathrm{nc} / 2.0 /$ and http://creativecommons.org/licenses/by-nc/2.0/legalcode. 


\section{Tables}

Table 1| Baseline characteristics of participants. Data are no (\%) unless stated otherwise

Intervention arm

\begin{tabular}{|c|c|c|c|c|}
\hline & \multicolumn{3}{|c|}{ Intervention arm } & \multirow[b]{2}{*}{ Total sample $(n=337)$} \\
\hline & Routine care $(n=112)$ & $\begin{array}{l}\text { Booklet self management } \\
\text { only }(n=113)\end{array}$ & $\begin{array}{l}\text { Booklet self management with } \\
\text { telephone support }(n=112)\end{array}$ & \\
\hline Male & $28(25)$ & $40(35)$ & $30(27)$ & $98(29)$ \\
\hline Age, years (mean, standard deviation) & $58.2(15.8)$ & $60.5(15.2)$ & $59.5(14.9)$ & $59.4(15.3)$ \\
\hline Left school aged $<18$ years & $80(71)$ & $94 / 111^{*}(85)$ & $95 / 110^{*}(86)$ & $269 / 333^{*}(81)$ \\
\hline Post school education & $68(61)$ & $62 / 111^{*}(56)$ & $67 / 110^{*}(61)$ & $197 / 333^{*}(59)$ \\
\hline $\begin{array}{l}\text { Duration of dizziness, months (mean, standard } \\
\text { deviation) }\end{array}$ & $67.9(111.0)$ & $657(75.6)$ & $65.8(88.6)$ & $66.5(93.0)$ \\
\hline $\begin{array}{l}\text { Consulted health professional in past year for } \\
\text { dizziness }\end{array}$ & $90(80)$ & $76(67)$ & $69(62)$ & $235(70)$ \\
\hline Prescribed medication for dizziness & $65(58)$ & $63(56)$ & $62(55)$ & $190(56)$ \\
\hline $\begin{array}{l}\text { Exceeded screening threshold for anxiety on } \\
\text { hospital anxiety and depression scale }\end{array}$ & $44(39)$ & $46(41)$ & $53(47)$ & $143(42)$ \\
\hline $\begin{array}{l}\text { Exceeded screening threshold for depression } \\
\text { on hospital anxiety and depression scale }\end{array}$ & $27(24)$ & $17(15)$ & $21(19)$ & $65(19)$ \\
\hline $\begin{array}{l}\text { Vertigo symptom scale-short form (mean, } \\
\text { standard deviation) }\end{array}$ & $13.8(10.7)$ & $12.6(7.7)$ & $13.4(9.6)$ & $13.5(9.6)$ \\
\hline
\end{tabular}




\begin{tabular}{|c|c|c|c|c|c|c|c|c|}
\hline & \multicolumn{6}{|c|}{ Intervention (mean score (standard deviation), no) } & \multicolumn{2}{|c|}{$\begin{array}{l}\text { Comparison (adjusted mean } \\
\text { difference }(95 \% \mathrm{Cl}), \mathrm{P})^{\star}\end{array}$} \\
\hline & \multicolumn{2}{|c|}{ Routine care } & \multicolumn{2}{|c|}{$\begin{array}{l}\text { Booklet self management } \\
\text { with telephone support }\end{array}$} & \multicolumn{2}{|c|}{$\begin{array}{c}\text { Booklet self management } \\
\text { only }\end{array}$} & \multirow{2}{*}{$\begin{array}{c}\text { Routine care } \\
\text { versus booklet } \\
\text { self management } \\
\text { with telephone } \\
\text { support }\end{array}$} & \multirow{2}{*}{$\begin{array}{c}\text { Routine care } \\
\text { versus bookle } \\
\text { self } \\
\text { management } \\
\text { only }\end{array}$} \\
\hline & Baseline & 12 weeks & Baseline & 12 weeks & Baseline & 12 weeks & & \\
\hline $\begin{array}{l}\text { Vertigo } \\
\text { symptom } \\
\text { scale-short } \\
\text { form }\end{array}$ & $\begin{array}{c}13.7(10.7) \\
n=98\end{array}$ & $\begin{array}{c}10.5(8.7) \\
n=98\end{array}$ & $\begin{array}{c}12.9(8.9) \\
n=85\end{array}$ & $8.3(7.9), n=85$ & $\begin{array}{c}12.2(7.9) \\
\mathrm{n}=92\end{array}$ & $\begin{array}{c}9.1(7.6) \\
n=92\end{array}$ & $\begin{array}{l}-1.79(-3.69 \text { to } \\
0.11), P=0.064\end{array}$ & $\begin{array}{c}-0.59(-2.45 \\
\text { to1.27), } P=0.532\end{array}$ \\
\hline $\begin{array}{l}\text { Patients } \\
\text { reporting } \\
\text { subjective } \\
\text { improvement }\end{array}$ & - & 40/107 (37)† & - & $57 / 100(57) \dagger$ & - & $62 / 105(59) \dagger$ & $\begin{array}{c}2.25(1.28 \text { to } \\
3.94) \neq, P=0.005\end{array}$ & $\begin{array}{c}2.41(1.39 \text { to } \\
4.20) \ddagger, P=0.002\end{array}$ \\
\hline $\begin{array}{l}\text { Vertigo } \\
\text { balance } \\
\text { subscale } \\
\end{array}$ & $\begin{array}{c}8.3(6.7) \\
n=98\end{array}$ & $\begin{array}{c}5.7(5.1) \\
n=98\end{array}$ & $\begin{array}{c}7.5(6.1) \\
n=85\end{array}$ & $4.6(5.2), n=85$ & $\begin{array}{c}7.7(5.7) \\
n=92\end{array}$ & $\begin{array}{c}5.0(5.1) \\
n=92\end{array}$ & $\begin{array}{l}-0.74(-1.98 \text { to } \\
0.51), P=0.246\end{array}$ & $\begin{array}{l}-0.46(-1.67 \text { to } \\
0.75), P=0.454\end{array}$ \\
\hline $\begin{array}{l}\text { Autonomic } \\
\text { anxiety } \\
\text { subscale }\end{array}$ & $\begin{array}{c}5.4(5.0) \\
n=98\end{array}$ & $\begin{array}{c}4.8(4.5) \\
n=98\end{array}$ & $\begin{array}{c}5.4(4.4) \\
n=85\end{array}$ & $3.7(3.9), n=85$ & $\begin{array}{c}4.4(3.6) \\
n=92\end{array}$ & $\begin{array}{c}4.1(3.8) \\
n=92\end{array}$ & $\begin{array}{l}-1.11(-2.03 \text { to } \\
-0.20), P=0.017\end{array}$ & $\begin{array}{l}-0.08(-1.00 \text { to } \\
0.82), P=0.869\end{array}$ \\
\hline $\begin{array}{l}\text { Dizziness } \\
\text { handicap } \\
\text { inventory } \\
\end{array}$ & $\begin{array}{l}32.9(18.4) \\
\quad n=96\end{array}$ & $\begin{array}{c}28.2(18.7) \\
n=96\end{array}$ & $\begin{array}{c}33.1(19.7) \\
n=85\end{array}$ & $\begin{array}{c}26.2(21.3) \\
n=85\end{array}$ & $\begin{array}{c}33.0(17.7) \\
n=92\end{array}$ & $\begin{array}{c}26.2(18.6) \\
n=92\end{array}$ & $\begin{array}{l}-2.25(-5.98 \text { to } \\
1.47), P=0.234\end{array}$ & $\begin{array}{l}-2.06(-5.74 \text { to } \\
1.61), P=0.269\end{array}$ \\
\hline \multicolumn{9}{|c|}{ Hospital anxiety and depression scale } \\
\hline Anxiety & $\begin{array}{c}6.91(4.30) \\
n=97\end{array}$ & $\begin{array}{c}6.3(4.13) \\
n=97\end{array}$ & $\begin{array}{c}6.80(4.18) \\
n=85\end{array}$ & $\begin{array}{c}5.79(4.27) \\
\mathrm{n}=85\end{array}$ & $\begin{array}{c}6.62(3.93) \\
n=92\end{array}$ & $\begin{array}{c}6.00(4.17) \\
n=92\end{array}$ & $\begin{array}{l}-0.46(-1.21 \text { to } \\
0.29), P=0.228\end{array}$ & $\begin{array}{l}-0.12(-0.88 \text { to } \\
0.65), P=0.763\end{array}$ \\
\hline Depression & $\begin{array}{c}4.23(3.42) \\
n=97\end{array}$ & $\begin{array}{c}4.03(3.44) \\
n=97\end{array}$ & $\begin{array}{c}\begin{array}{c}4.12(3.22) \\
\mathrm{n}=85\end{array}\end{array}$ & $\begin{array}{c}3.92(3.56) \\
n=85\end{array}$ & $\begin{array}{c}4.26(3.47) \\
\mathrm{n}=92\end{array}$ & $\begin{array}{c}3.77(3.54) \\
n=92\end{array}$ & $\begin{array}{l}-0.02(-0.66 \text { to } \\
0.62), P=0.954\end{array}$ & $\begin{array}{l}-0.28(-0.93 \text { to } \\
0.37), P=0.396\end{array}$ \\
\hline$E Q-5 D$ & $\begin{array}{c}0.79(0.22) \\
n=94\end{array}$ & $\begin{array}{c}0.79(0.27) \\
\mathrm{n}=94\end{array}$ & $\begin{array}{c}0.75(0.27) \\
\mathrm{n}=84\end{array}$ & $\begin{array}{c}0.80(0.24) \\
n=84\end{array}$ & $\begin{array}{c}0.78(0.24) \\
\mathrm{n}=89\end{array}$ & $\begin{array}{c}0.82(0.19) \\
\mathrm{n}=89\end{array}$ & $\begin{array}{l}0.04(-0.02 \text { to } \\
0.10), P=0.156\end{array}$ & $\begin{array}{l}0.04(-0.02 \text { to } \\
0.09), P=0.179\end{array}$ \\
\hline
\end{tabular}

*All analyses adjusted for baseline levels of the stratification variable, the vertigo symptom scale-short form, and for baseline levels of the dependent variable. †Data are reporting/total number of patients (\%).

‡Data are odds ratio $(95 \%$ confidence interval). 


\begin{tabular}{|c|c|c|c|c|c|c|c|c|}
\hline & \multicolumn{6}{|c|}{ Intervention (mean score (standard deviation), no) } & \multicolumn{2}{|c|}{$\begin{array}{l}\text { Comparison (adjusted mean difference } \\
\qquad(95 \% \mathrm{Cl}), \mathrm{P})^{\star}\end{array}$} \\
\hline & \multicolumn{2}{|c|}{ Routine care } & \multicolumn{2}{|c|}{$\begin{array}{l}\text { Booklet self management with } \\
\text { telephone support }\end{array}$} & \multicolumn{2}{|c|}{$\begin{array}{l}\text { Booklet self management } \\
\text { only }\end{array}$} & \multirow{2}{*}{$\begin{array}{l}\text { Routine care } \\
\text { versus booklet } \\
\text { self management } \\
\text { with telephone } \\
\text { support }\end{array}$} & \multirow{2}{*}{$\begin{array}{c}\text { Routine care } \\
\text { versus booklet } \\
\text { self managemen } \\
\text { only }\end{array}$} \\
\hline & Baseline & One year & Baseline & One year & Baseline & One year & & \\
\hline $\begin{array}{l}\text { Vertigo } \\
\text { symptom } \\
\text { scale-short } \\
\text { form }\end{array}$ & $\begin{array}{c}13.8(10.7) \\
n=89\end{array}$ & $\begin{array}{c}11.0(8.7) \\
n=89\end{array}$ & $\begin{array}{c}13.4(10.0) \\
n=86\end{array}$ & $8.3(8.5), n=86$ & $\begin{array}{c}11.8(7.9) \\
n=88\end{array}$ & $7.6(6.2), n=88$ & $\begin{array}{l}-2.52(-4.52 \text { to } \\
-0.51), P=0.014\end{array}$ & $\begin{array}{l}-2.43(-4.27 \text { to } \\
-0.60), P=0.010\end{array}$ \\
\hline $\begin{array}{l}\text { Patients } \\
\text { reporting } \\
\text { subjective } \\
\text { improvement }\end{array}$ & - & $47 / 99(47 \%) \dagger$ & - & $66 / 95(69 \%) \dagger$ & - & $60 / 100(60 \%) \dagger$ & $\begin{array}{c}2.56(1.41 \text { to } 4.66) \ddagger \\
P=0.002\end{array}$ & $\begin{array}{c}1.63(0.93 \text { to } 2.87) \ddagger \\
\mathrm{P}=0.091\end{array}$ \\
\hline $\begin{array}{l}\text { Vertigo } \\
\text { balance } \\
\text { subscale }\end{array}$ & $\begin{array}{c}8.2(6.6) \\
n=89\end{array}$ & $5.7(4.9), n=89$ & $7.7(6.7), \mathrm{n}=86$ & $4.6(5.5), n=86$ & $7.2(5.5), n=88$ & $4.3(4.0), \mathrm{n}=88$ & $\begin{array}{c}-1.07(-2.2 \text { to } 1.0) \\
P=0.073\end{array}$ & $\begin{array}{l}-0.92(-2.23 \text { to } \\
0.39), P=0.168\end{array}$ \\
\hline $\begin{array}{l}\text { Autonomic } \\
\text { anxiety } \\
\text { subscale }\end{array}$ & $\begin{array}{c}5.6(5.1) \\
n=89\end{array}$ & $5.3(4.6), n=89$ & $5.6(4.8), n=86$ & $3.6(4.0), n=86$ & $4.5(3.7), n=88$ & $3.3(3.2), n=88$ & $\begin{array}{l}-1.64(-2.60 \text { to } \\
-0.68), P=0.001\end{array}$ & $\begin{array}{l}-1.38(-2.31 \text { to } \\
-0.46) P=0.004\end{array}$ \\
\hline $\begin{array}{l}\text { Dizziness } \\
\text { handicap } \\
\text { inventory } \\
\end{array}$ & $\begin{array}{c}33.7(18.1) \\
n=89\end{array}$ & $\begin{array}{c}29.2(18.8) \\
n=89\end{array}$ & $\begin{array}{c}33.7(18.1) \\
\quad n=86\end{array}$ & $\begin{array}{c}29.2(18.8) \\
n=86\end{array}$ & $\begin{array}{c}31.2(17.6) \\
\quad n=88\end{array}$ & $\begin{array}{c}23.0(17.7) \\
n=88\end{array}$ & $\begin{array}{l}-4.27(-8.70 \text { to } \\
-0.74), P=0.020\end{array}$ & $\begin{array}{l}-4.37(-8.5 \text { to } \\
-0.21) P=0.040\end{array}$ \\
\hline \multicolumn{9}{|c|}{ Hospital anxiety and depression scale } \\
\hline Anxiety & $\begin{array}{c}7.15(4.27) \\
\mathrm{n}=89\end{array}$ & $\begin{array}{c}7.01(4.27) \\
\mathrm{n}=89\end{array}$ & $\begin{array}{c}6.79(4.33) \\
n=86\end{array}$ & $\begin{array}{c}5.66(4.40) \\
n=86\end{array}$ & $\begin{array}{c}6.68(3.99) \\
n=88\end{array}$ & $\begin{array}{c}6.03(4.51) \\
n=88\end{array}$ & $\begin{array}{l}-1.05(-1.89 \text { to } \\
-0.22), P=0.014\end{array}$ & $\begin{array}{l}-0.59(-1.48 \text { to } \\
0.31), P=0.200\end{array}$ \\
\hline Depression & $\begin{array}{c}4.51 \text { (3.68) } \\
\mathrm{n}=89\end{array}$ & $\begin{array}{c}4.60(4.02) \\
\mathrm{n}=89\end{array}$ & $\begin{array}{l}4.11 \text { (3.52) } \\
\qquad \mathrm{n}=86\end{array}$ & $\begin{array}{c}3.41(3.41) \\
\mathrm{n}=86\end{array}$ & $\begin{array}{c}4.00(3.44) \\
n=88\end{array}$ & $\begin{array}{c}3.82(3.62) \\
\mathrm{n}=88\end{array}$ & $\begin{array}{l}-0.87(-1.57 \text { to } \\
-0.17), P=0.016\end{array}$ & $\begin{array}{l}-0.35(-1.13 \text { to } \\
0.44), P=0.387\end{array}$ \\
\hline$E Q-5 D$ & $\begin{array}{c}0.79(0.21) \\
n=86\end{array}$ & $\begin{array}{c}0.79(0.26) \\
n=86\end{array}$ & $\begin{array}{l}0.75(0.29) \\
n=85\end{array}$ & $\begin{array}{c}0.80(0.28) \\
n=85\end{array}$ & $\begin{array}{l}0.83(0.23) \\
n=85\end{array}$ & $\begin{array}{c}0.82(0.18) \\
n=85\end{array}$ & $\begin{array}{l}0.04(-0.01 \text { to } 0.10) \\
\quad P=0.107\end{array}$ & $\begin{array}{c}0.02(-0.03 \text { to } 0.07) \\
P=0.343\end{array}$ \\
\hline
\end{tabular}

*All analyses adjusted for baseline levels of the stratification variable, the vertigo symptom scale-short form, and for baseline levels of the dependent variable. †Data are reporting/total number of patients (\%).

fData are odds ratio (95\% confidence interval). 
Table 4| Bootstrapped cost effectiveness analysis (complete case analysis)

\begin{tabular}{|c|c|c|c|c|c|}
\hline & $\begin{array}{l}\text { QALY or point change on } \\
\text { vertigo symptom scale-short } \\
\text { form ( } 95 \% \text { percentiles) }\end{array}$ & $\begin{array}{l}\text { Total costs ( } 95 \% \\
\text { percentiles) }\end{array}$ & $\begin{array}{l}\text { Incremental QALY or } \\
\text { vertigo symptom } \\
\text { scale-short form }\end{array}$ & Incremental costs & $\begin{array}{l}\text { Incremental cost } \\
\text { effectiveness ratio }\end{array}$ \\
\hline \multicolumn{6}{|l|}{ Cost per QALY } \\
\hline Routine care & $0.80(0.76$ to 0.85$)$ & $£ 35$ (20 to 51$)$ & & Dominated $^{*}$ & \\
\hline $\begin{array}{l}\text { Booklet self management } \\
\text { only }\end{array}$ & $0.83(0.79$ to 0.86$)$ & $£ 31(12$ to 55$)$ & & - & \\
\hline $\begin{array}{l}\text { Booklet self management } \\
\text { with telephone support }\end{array}$ & $0.85(0.80$ to 0.90$)$ & $£ 60$ (46 to 77$)$ & 0.022 & $£ 29$ & $£ 1363$ \\
\hline \multicolumn{6}{|c|}{ Cost per point change on vertigo symptom scale-short form } \\
\hline Routine care & $3.2(1.4$ to 5.0$)$ & $£ 35$ (21 to 51$)$ & & Dominated $^{*}$ & \\
\hline $\begin{array}{l}\text { Booklet self management } \\
\text { only }\end{array}$ & $4.2(2.7$ to 5.8$)$ & $£ 31$ (12 to 55$)$ & & - & \\
\hline $\begin{array}{l}\text { Booklet self management } \\
\text { with telephone support }\end{array}$ & $4.5(2.7$ to 6.3$)$ & $£ 60(46$ to 77$)$ & 0.227 & $£ 29$ & $£ 129$ \\
\hline
\end{tabular}

Welephone support

*Booklet self management only group dominates the routine care group-that is, routine care was less effective and slightly more costly than booklet self management only. It is considered standard practice to compare groups with the next best option that is not dominated. ${ }^{57}$ Therefore, booklet self management with telephone support was compared with booklet self management only. 


\section{Figures}

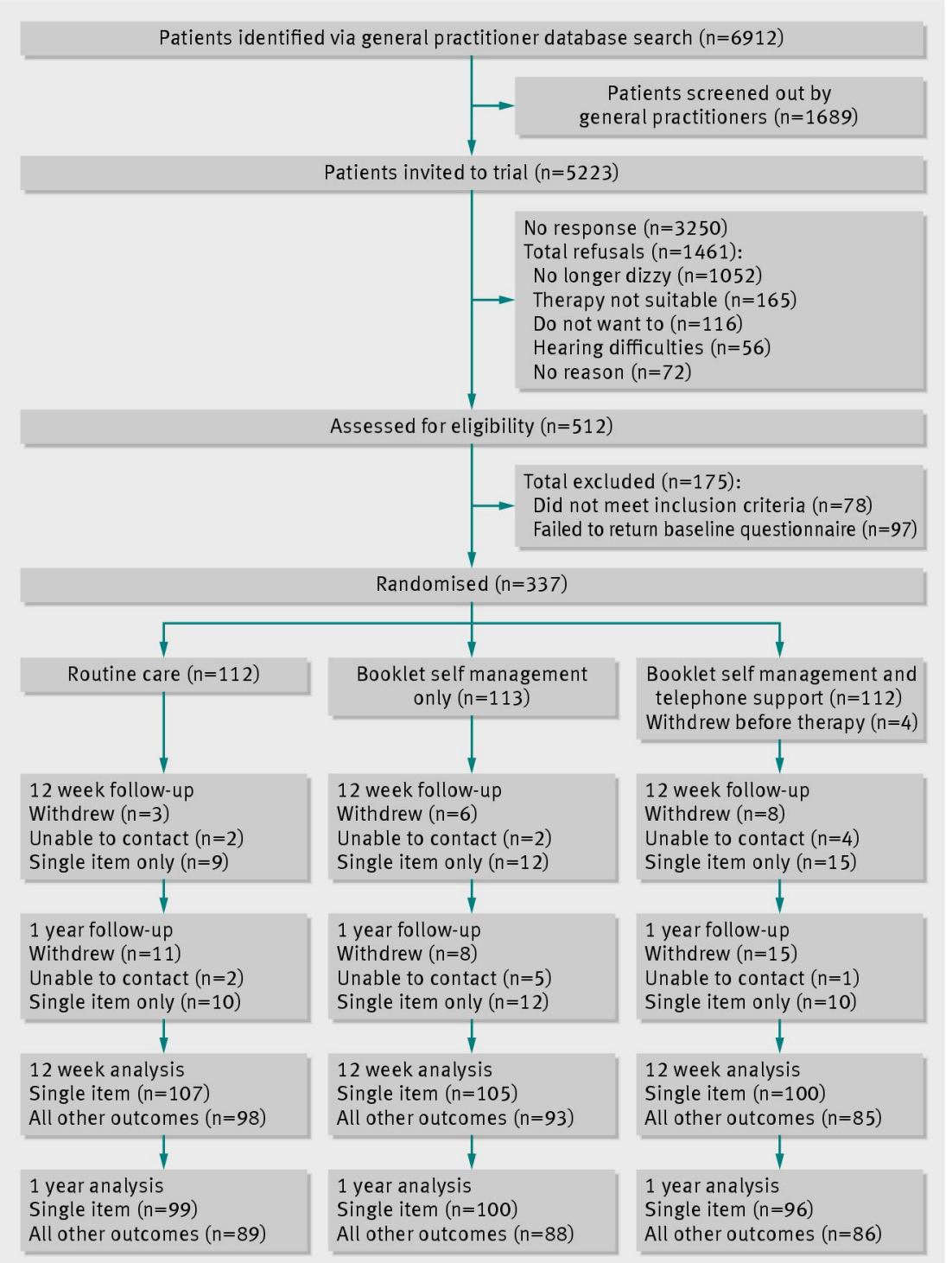

Fig 1 CONSORT diagram showing patient flow through trial

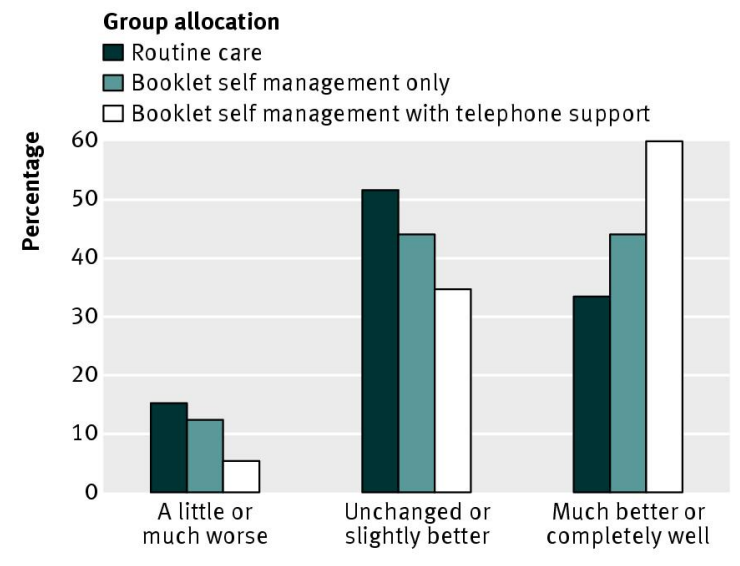

Subjective symptom report (compared with baseline)

Fig 2 Pattern of subjective improvement at one year follow-up 


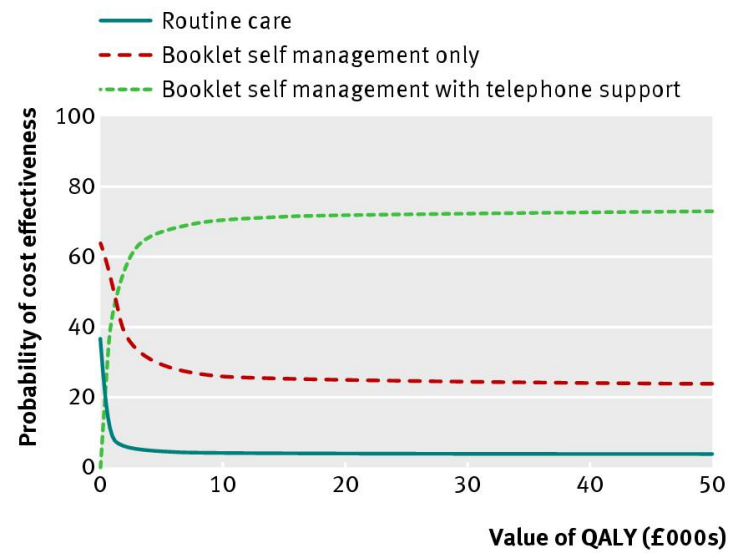

Fig 3 Cost effectiveness acceptability curve showing change in the probability of cost effectiveness as the value of a QALY changes (NHS costs only) 